\title{
Wolff-Parkinson-White syndrome in association with atrial reciprocal rhythm and reciprocating tachycardia
}

\author{
Myron H. Luria and C. Gordon Hale \\ From the Division of Medicine, Saint Luke's Hospital, Cleveland, Ohio, U.S.A.
}

$A$ patient with the Wolff-Parkinson-White syndrome and both atrial reciprocal rhythm and atrial reciprocating tachycardia is reported. The association of these entities is rare and further supports the concept of the bypass theory. Moreover, this association emphasizes the significance of reciprocal rhythm in the genesis of paroxysmal tachycardia.

The Wolff-Parkinson-White (WPW) syndrome is reflected by a short PR interval and a widened $Q R S$ complex, with a slurred initial component - the delta wave. The mechanism of this syndrome is thought to be due to the presence of a bypass within the AV junction an additional $\mathrm{AV}$ conduction channel which permits rapid AV conduction and consequent pre-excitation of the ventricles. The presence of an additional pathway is supported by the rare association of atrial reciprocal rhythm or its repetitive form, atrial reciprocating tachycardia, with the WPW syndrome. Since atrial reciprocal rhythm can only take place in the presence of an additional AV junctional bypass, the occurrence of this mechanism with the WPW syndrome supports the concept of the bypass theory. The association of these two entities is exceedingly rare - only 6 cases have thus far been reported (Wolff, 1959; Harris, Semler, and Griswold, 1964; McHenry, Knoebel, and Fisch, 1966; Burchell et al., I967; Massumi, Kistin, and Tawakkol, I967; Roelandt and Van der Hauwaert, I968). The following is another example of this phenomenon.

\section{Case Report}

The electrocardiogram was recorded from a 28year-old male Negro with hypertension who complained of periods of rapid heart action. During a routine electrocardiogram (Fig. I), which reveals a Type B WPW syndrome, an episode of paroxysmal tachycardia developed spontaneously. After carotid sinus compression, the electrocardiogram (Fig. 2, a continuous strip of standard lead II) showed WPW complexes interspersed between complexes of more normal configuration (Ist, 5 th, 6th, 7th, 8th, and 9th QRS complexes in the upper strip). Two atrial extrasystoles are present in the upper strip. They are conducted with a prolonged PR interval $(0.3 \mathrm{I} \mathrm{sec}$.) resulting in the 6th and 9th QRS complexes. The complexes are followed by an inverted $P$ wave - the $P^{1}$ deflection. A similar phenomenon is seen in the middle of the lower strip. The $\mathbf{P}^{1}$ deflection was observed many times and was always associated with a prolonged PR interval. The onset of a paroxysmal tachycardia is seen towards the end of the lower strip. The beginning of the tachycardia is complicated by a ventricular extrasystole which does not disturb the tachycardia.

\section{Discussion}

Atrial reciprocal rhythm occurs when a sinus or atrial impulse during its passage through the $\mathrm{AV}$ junction divides into two activation fronts: one continuing on to activate the ven-

FIG. I Electrocardiogram showing the WolffParkinson-White syndrome, Type B (see text).

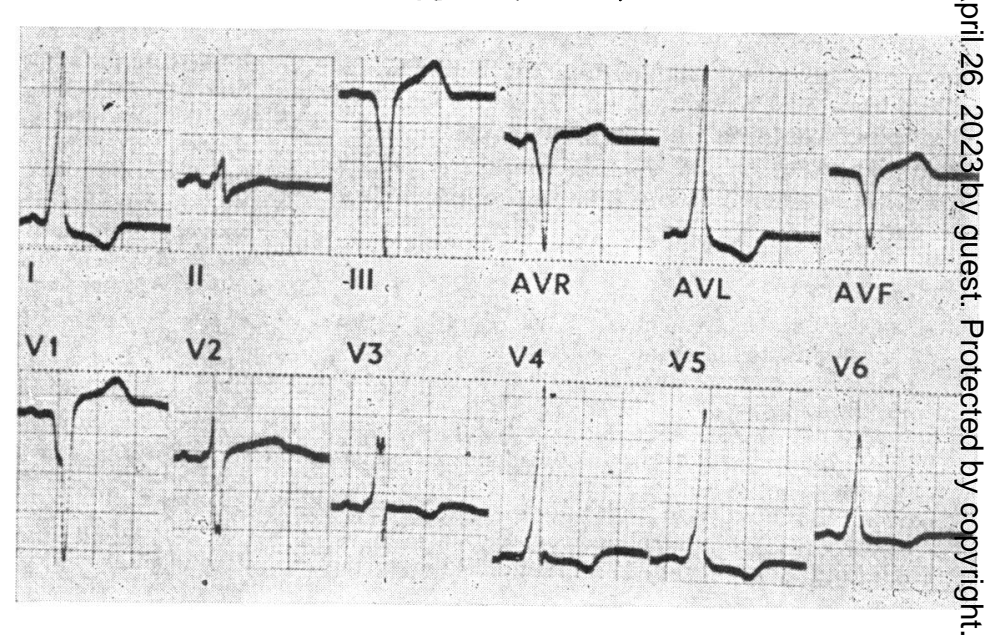




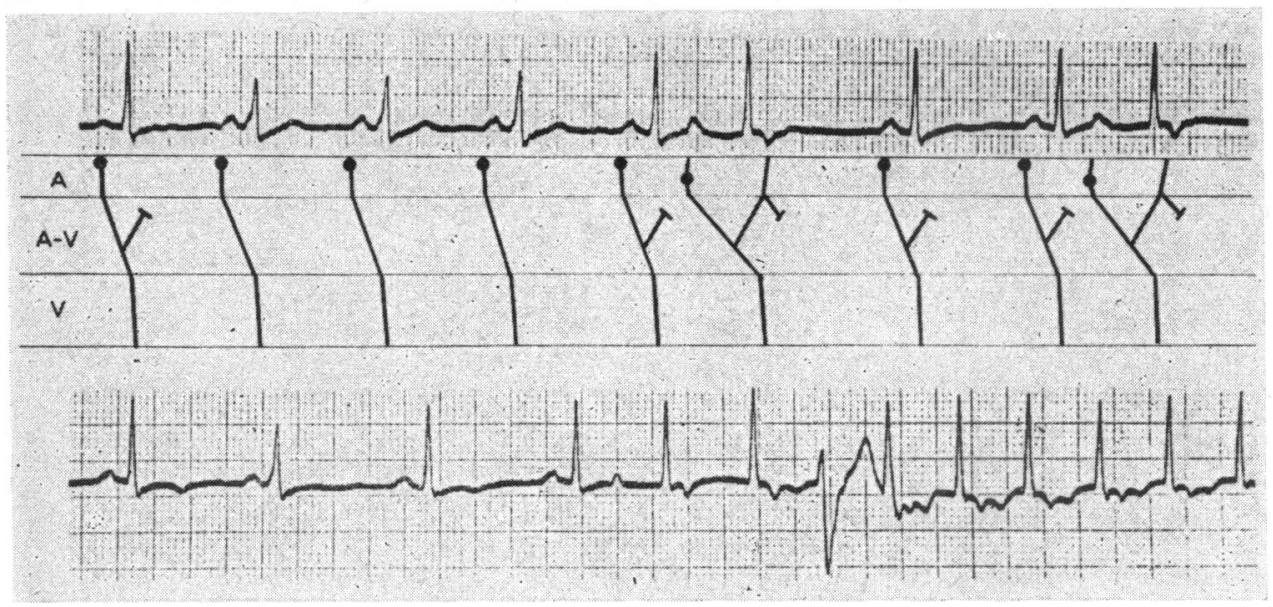

FIG. 2 Electrocardiogram (lead II, continuous strip) showing atrial reciprocal rhythm and atrial reciprocating tachycardia (see text).

tricles and the other coming back to reactivate the atria. When the phenomenon becomes repetitive, it has been termed 'atrial reciprocating rhythm' because of historical priorities (Kistin, 1965). Perhaps a clearer and more inclusive description of the latter is 'atrial reciprocating tachycardia'.

The diagnosis of atrial reciprocal rhythm depends chiefly on the demonstration of a selective linkage to a prolonged PR interval. The long PR interval is necessary to allow the atrial chambers sufficient recovery time before the arrival of the returning impulse. In the present patient a prolonged PR interval following an atrial extrasystole was shown on several occasions (Fig. 2). Each subsequent QRS complex was then followed by an inverted $P$ wave - the $P^{1}$ deflection. It may be construed that the $\mathrm{P}^{1}$ deflection represents an atrial extrasystole and not retrograde atrial activation. However, it would be fortuitous for true atrial extrasystoles to be so selectively linked to prolonged PR intervals. Furthermore, if the $\mathrm{P}^{1}$ deflection were due to successive atrial extrasystoles, it would be remarkable that the first atrial extrasystole always has an upright $P$ wave, whereas subsequent extrasystoles always have inverted $P$ waves. Atrial reciprocating tachycardia thus implies initiation and repetitive re-entry of a single impulse and not repetitive ectopic impulse formation.

For the return of the dissociated activation front of atrial reciprocal rhythm, an alternate pathway must be postulated since the original pathway would be refractory. An additional pathway is also postulated in the WPW syndrome. If a sinus impulse finds the anatomically anomalous pathway of the WPW syn- drome refractory, it will be conducted through the normal pathway to the ventricles and may return through the anomalous pathway to the atria. Characteristically, the typical fusion beats of the WPW syndrome will not be present in atrial reciprocal rhythm because of anterograde conduction entirely through the normal pathway (Fig. 2). The occurrence of reciprocal rhythm and the WPW syndrome at different times in the same patient is therefore not surprising. Indeed, in a report of a patient with paroxysmal atrial reciprocating tachycardia (Schamroth, I960), the WPW syndrome was predictably found 6 months later (L. Schamroth, personal communication, I968).

The incidence of atrial reciprocal rhythm as the initiating mechanism in paroxysmal tachycardia associated with the WPW syndrome is unknown, and has been rarely reported because of the understandable difficulty in recording the onset of a paroxysmal tachycardia. However, its importance appears clear. The high incidence of paroxysmal tachycardia in the WPW syndrome may be largely related to the accessibility of an alternate pathway for the development of atrial reciprocal rhythm and reciprocating tachycardia.

\section{References}

Burchell, H. B., Frye, R. L., Anderson, M. W., and McGoon, D. C. (1967). Atrioventricular and ventriculoatrial excitation in Wolff-Parkinson-White syndrome (Type B): temporary ablation at surgery. Circulation, 36, 663.

Harris, W. E., Semler, H. J., and Griswold, H. E. (1964). Reversed reciprocating paroxysmal tachycardia controlled by guanethidine in a case of WolffParkinson-White syndrome. American Heart fournal, 67, 812.

Kistin, A. D. (1965). Atrial reciprocal rhythm. Circulation, 32, 687.

McHenry, P. L., Knoebel, S. B., and Fisch, C. (1966). The Wolff-Parkinson-White (WPW) syndrome with supernormal conduction through the anomalous bypass. Circulation, 34, 734. 
Massumi, R. A., Kistin, A. D., and Tawakkol, A. A. (1967). Termination of reciprocating tachycardia by atrial stimulation. Circulation, 36, 637.

Roelandt, J., and Van der Hauwaert, L. G. (1968). Atrial reciprocal rhythm and reciprocating tachycardia in Wolff-Parkinson-White syndrome. Circulation, 38, 64 .
Schamroth, L. (1960). Reversed reciprocating paroxysmal tachycardia and its relationship to the WolffParkinson-White syndrome. American Heart fournal, 59, 506.

Wolff, L. (1959). Anomalous atrioventricular excitation (Wolff-Parkinson-White syndrome). Circulation, 19, 14.

$\underline{0}$ 